\title{
Cross-Linguistic Influence at Lexical Level: An Exploratory Study of How Arabic Speakers Acquire Chinese Onomatopoeias
}

\author{
Rashidah Albaqami ${ }^{1}$ \\ ${ }^{1}$ FLD, Taif university, Saudi Arabia \\ Correspondence: Rashidah Albaqami, FLD, Taif university, Saudi Arabia. E-mail: r.mohamad@tu.edu.sa
}

Received: April 20, 2020

Accepted: May 23, $2020 \quad$ Online Published: May 31, 2020

doi:10.5539/ijel.v10n4p159

URL: https://doi.org/10.5539/ijel.v10n4p159

\begin{abstract}
Empirical evidence suggests that the first language (L1) has a fundamental role in the second language (L2) development, especially at the lexical level. Studies of L2 development have reported a relationship between negative L1 transfer and L2 poor comprehension. It is evident that cross-linguistic transfer might also take place during the course of third language (L3) development and that the impact may be from L1. At the lexico-semantic level, this study examines onomatopoeia as a property of L3 acquisition that requires Arabic learners of Chinese to identify some new lexicons with meanings and functions that might not exist in their L1. Given that onomatopoeia, in general, is often not taught sufficiently and explicitly in many language classroom contexts across the world, the purpose of the current study is to determine the extent to which transfer from L1 influence L3 comprehension and to establish the conditions in which L1 was the prevailing impact. A total of 45 Arabic native speakers were asked to translate a number of Mandarin Chinese onomatopoeic expressions $(n=20)$ into Arabic. The findings suggest that Arabic learners find Mandarin Chinese onomatopoeic expressions, that neither have Arabic nor English direct counterparts, significantly challenging. The study concludes that enhancing awareness of lexical transfer through a focused consideration of the common difficulties seems crucial for L3 learners to attain comprehensive mastery.
\end{abstract}

keywords: onomatopoeias, lexical-semantic transfer, Arabic, English, Mandarin Chinese

\section{Introduction}

Chinese language will soon be introduced as a curriculum at all stages of education across Saudi Arabia (Arab News, February 22, 2019). Learning Chinese is expected to enhance cultural and financial ties. However, due to cross linguistic differences and cultural diversity, several learnability issues are expected to arise at different levels after the introduction of Chinese language in the KSA. Mandarin Chinese is one of the languages rich in onomatopoeia. Arabic, on the other hand, has a relatively few onomatopoeias. There seems a scarcity of studies investigating how learners having L1 (such as Arabic) with a small number of onomatopoeic expressions acquire languages (such as Mandarin Chinese) as compared to L1 that possesses a lot of onomatopoeic expressions. Hence, this paper investigates the role of previously acquired languages L1 (Arabic) on the L3 (Mandarin Chinese) development especially at early stages. This study aims to contribute to this somewhat neglected area of research by exploring the role of L1 in L3 development in a new context.

\section{Literature Review}

It is generally acknowledged that the sound for the word (the so-called symbolic words) of a certain meaning is arbitrary; hence, there is commonly an association between sound and meaning. This, nevertheless, is not unquestionably accurate, as it ignores the presence of a class of words, called Onomatopoeias (mimetic words), which emerge in the everyday usage of all languages relatively often. Onomatopoeias have an iconic nature (i.e., the association between forms and meanings is not arbitrary and forms represent sounds in the nature) (Khademi et al., 2014). Onomatopoeias are sound symbolism — namely, words whose articulations indicate their meanings such as the word moo used for cow's sound (Fromkin et al., 2003, p. 7). In other words, onomatopoeias are defined as the imitative constructing of words from natural sounds and are described as a class of words that phonetically imitate the sounds that they represent. The term 'Onomatopoeia' is derived from two Greek words, onoma 'name' and poiein 'to make', hence onomatopoeia means 'to make a name'. Kambuziya and Zeinolabedin (2014, p. 220) divided onomatopoeic expressions into four main specific categories: 1) human sounds such as wah-wah that is used to represent the sound of a crying baby; 2) animal calls such as woof which is the most common depiction for a dog barking in English; 3) sounds made by nature such as crackle crackle that is used to depict the sound of fire 
as well as 4) other miscellaneous sounds such as machinery sounds, e.g., the sound of a clock typically described as tick tock.

Onomatopoeias, distinctive class of words and typical expressions used in verbal and printed forms of language, emerge frequently in daily use of language due to its imitative nature. It is considered as a common phenomenon which originates across linguistically. Onomatopoeias, in ancient Greek, were considered as evidences of how natural languages were. Evidence suggests that language was originated from natural sounds in the world. A number of linguists argue that they were the initial forms of human language; i.e., initial words human beings uttered when language was initially advanced. These sounds, that are linked with natural forms, subsequently develop to shape other words with associated meanings. Consider, for instance, the English prefix $g l$ - can signify an object that is shining (e.g., glimmer, glint, glitter, gleam). Furthermore, onomatopoeias are productive as they can be nouns, verbs, adjectives and adverbs, which all become part of our daily language. The word crack, for instance, is not only the sound that is resulted by breaking something, but also the action of breaking something (e.g., a door). Onomatopoeia typically functions as a word specifying sound 'voice' such as roar 'the sound of a lion'; however, many onomatopoeia words also convey states, actions, feelings and emotions. These words include mimicking manner of movement (e.g., zigzag) or physical or mental state (e.g., sluggish) (Tamori \& Schourup, 1999, p. 10).

Consider the word boom, for instance, which merely is a sound effect, however, it is very beneficial for storytelling resulting in more meaningful, interesting fun and vibrant effect. That is, onomatopoeia is a figure of speech principally advantageous for rhetorical impact (Thomas \& Hill, 2012). Comic books comprise a huge number of onomatopoeic words which boosts its beauty efficiently. As the hearer or the reader can recognise the meaning most effortlessly by direct imitation, onomatopoeias are the most evident manner to define actions (e.g., bang 'short loud noise') and animals (e.g., meow 'cat voice'), which establish the most informative segments of the dialogue. More examples of onomatopoeias are also found in many advertisements which enrich the beauty of the message efficiently and deliver it in a better manner. That is, onomatopoeias are not only playthings which children use but also adults use many of them daily. Languages include many onomatopoeias to portray actions. Basically, there are four key functions for onomatopoeias including to boost the contents of scripts by providing more vibrant portrayal of the setting, to enhance the amount of musicality, to expand the reader's impression towards the meaning and similarly to enlarge the reality of the setting, so as the reader can have an authentic acoustic perception of the entire image (Seyyedi \& Akhlaghi, 2013).

Languages rich with onomatopoeia are more expressive and simplify comprehension of the content to the hearer or reader. However, onomatopoeia is considered a problematic area not only for L2/L3 learners but also for translators. As they are commonly used in daily conversations, it is crucial to make L2/L3 learners attentive that this is a critical area to master for a fruitful communication. The study of onomatopoeias seems, nevertheless, insufficient and inadequate given its significant role in the development of language and considered a somewhat neglected area. Several linguists considered onomatopoeias as "second class citizens among words, since they are often polysemous, while at the same time, paradoxically, applicable to only a narrow semantic range" (Falk, 1978, p. 60). Therefore, omission of onomatopoeia is used as a method of interpretation, particularly in cases where onomatopoeic words do not have literal counterparts in the L2. Sometimes, learners use other methods including explicative rewordings or grouping of many words and interestingly loan words are used in this regard. However, these methods might change the intended meaning.

Interestingly, learners might not face the same amount of difficulty with all onomatopoeia. MaÕrifatil (2008) states that there are three types of onomatopoeia which reflects the relationship between meaning and function: (i) Direct onomatopoeias in which the forms are similar to the actual natural sound they imitate, such as roar, (ii) Associative onomatopoeia is a form which indirectly expresses the sound that it indicates to, i.e., whip and (iii) Exemplary onomatopoeia is "based on the amount and character of the physical work done by the speaker in uttering the word" (Yaqubi et al., 2018, p. 208) such as nimble. Learners might find direct onomatopoeias more straightforward to master due to its iconic nature. The next section examines onomatopoeias cross-linguistically.

\subsection{Cross-Linguistic Onomatopoeias}

As a communal source, the same onomatopoeia sound in a different language is constrained by the distinctive phonological systems, resulting in differences between them. Though a specific sound is perceived analogously by people of dissimilar languages and cultures, it is frequently articulated by the use of distinctive consonant strings in different linguistic systems. Hence, onomatopoeias are subjected to cross-linguistic variations.

Consider the sound of a horse trotting, it may be symbolized as clip clop in English, Pa-ta-clop in French, pocotó pocotó in Portuguese, kataklop kataklop in Dutch, deregin-deregin in Arabic, pütikā pütikā in Persian and tag bag 
in Bengali. Likewise, the sound of water dripping is expressed through drip drop in English, csöp-csöp in Hungarian, tip tip in Finnish, plin plin in Italian, pota pota in Japanese, tik tik in Arabic and şıp şıp in Turkish. One can argue that learners of the target language might find forms that are familiar to them or similar to those of their L1 much effortless to master and hence successfully approach a successful comprehension. For instance, consider the different forms for kissing in English; mouah, smack, mwah, and smooch. French speakers of English might find mouah and smack much acquirable than smooch. Given the fact that the former two forms identically mirror those of their L1, from a phonological standpoint. While Arabic speakers of English might find mouah much easier than smack and smooch as Arabic typically selects only one form for kissing which is $ح^{\prime}$ 'mwah', which is relatively comparable to only one form in English.

As far as the present study is concerned, it deals with Arabic, English and Mandarin Chinese which belong to three different language families. Arabic is a member of the family of Semitic languages. English belongs to the Germanic family, which is part of the Indo-European family. Whereas, Mandarin Chinese belongs to Sino-Tibetan (Campbell, 2006). Jassem (2014) argues that Arabic and English are argued to be inherently related but are originated from a single language, claimed to be Arabic; the source or radical language. Jassem (2014) reviews comparative historical research that compares every word in English with its Arabic equivalent based on its origin and development in English and he reported many studies (e.g., Harper, 2014; Pyles \& Algeo, 1993) and in Arabic (e.g., Ibn Manzour, 2013; Altha3aalibi, 2011; Ibn Seedah, 1996). Jassem (2014) argues that Mandarin Chinese is not only inherently related to Arabic but also to English. However, they vary at different levels: phonetically, morphologically, and lexically. The next section attempts to determine the degree of the relation linking Arabic, English and Mandarin Chinese onomatopoeic expressions. That is, how much likeness (if any) does exist among the three languages.

\subsubsection{Onomatopoeias in Arabic}

According to Seyyedi and Akhlaghi (2013), only a limited number of onomatopoeias are recognized in the Holy Qur'an which was written in Arabic language for Muslims. That is, out of nearly 77,701 forms, there are only 9 of them onomatopoeic; 3 onomatopoeias portray sounds of animals (e.g., mooing of a cow), 2 onomatopoeias express sounds of nature (e.g., thunder), and 4 onomatopoeias depict human sounds (e.g., whisper). Seyyedi and Akhlaghi (2013) claim that the low number of onomatopoeias is attributed to the multiplicity of the Arabic tribes (about 360) in early ages of Islam and the dialectical and phonetic dissimilarities among them owing to geographical, racial, and social and political factors although the main language was that of the Quraish tribe. Beside difficult interpretation of onomatopoeia, cases in which omission or superfluous clarifications would occur are not frequent Thus, Allah incorporated only a small number of onomatopoeias in the Holy Qur'an. For detailed account and further examples of Arabic onomatopoeias, refer to Al-Jahidh (1988), Al-Zubbaidi (2014), and Alameer (2019).

\subsubsection{Onomatopoeias in English}

English, compared to other languages such as Arabic, is considered a highly rich language with onomatopoeias. It has numerous expressions that were coined to sound like what they symbolize. English might have several onomatopoeias for the same sound; i.e., different forms for the same meaning. For instance, crashing in English is depicted by boom, bam, bang, crash, clash, pow, wham, thud, clang, slam, among others. Interestingly, due to the productive nature of English, it coins onomatopoeia for some objects that are borrowed from other cultures such as Hubble-bubble.

\subsubsection{Onomatopoeias in Mandarin Chinese}

Chinese, which is the largest language in the world, has several dialects. Owing to its remarkably huge population, connection with the capital city, and the adoption of the government, Mandarin, nevertheless, has been chosen to be the official language of China. Chinese onomatopoeias, or 象声词 'xiàng shēng cí', can typically be recognisable because the majority of words have the feature of kǒu 'radical' on the left-hand side. This is done because the mouth radical typically represents a sound being made. However, onomatopoeia seems more limited in Chinese than in English as Chinese has only a restricted set of consonant-vowel arrangements rather than the apparently countless variations in English. Furthermore, Chinese onomatopoeia has to be printed in Chinese characters, which may be challenging to invent novel methods to symbolise sounds that do not originally exist (Yi, 2005, 2007). Interestingly, similar to English, Chinese might have several onomatopoeias for the same sound; i.e., different forms for the same meaning. For instance, it has different forms of laughter not just the well-known 哈 哈 'hā hā', including 呵呵 'hē hē', 嘻嘻 'xî̀ xî̀' and 嘿嘿 'hēi hēi'.

The three languages have common features. For instance, they might have one, two or even three-character onomatopoeias, such as Boom! toot toot, cock a doodle doo, receptively. In Mandarin Chinese onomatopoeic expressions, furthermore, it can have four characters such as sound of firecrackers 稀里哗啦 ' $x \overline{1}$ lĩ huā lā'. 
Having said that the same creatures usually produce identical sounds, they might have different forms across different languages. Birds are singing in Arabic as سبقسِ 'siqsiq', غريو زيو 'ziw ziw'. They chirp chirp, tweet tweet, cheep cheep, peep peep in English and 䶷䶷喳喳 ‘ jī jī zhā zhā’ in Mandarin Chinese. Furthermore, not all the different types of birds have onomatopoeic forms across languages. Many birds have different onomatopoeic expressions in English such as cluck cluck, bok bok bok, bok bok b'gawk for chicken clucking, cock a doodle doo for roster crowing, gobble gobble for turkey calling, gobble gobble for goose calling and honk honk

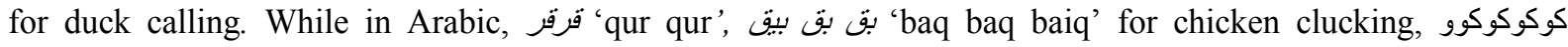

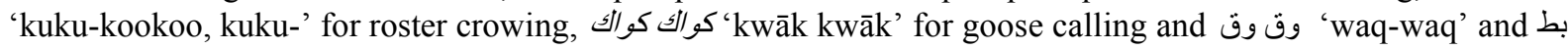
بط 'bat bat' for duck calling. However, it has no specific onomatopoeic expression for turkey calling, for example. Likewise, in Mandarin Chinese, not all birds have specific onomatopoeic expressions such as turkey calling or goose calling. Yet, it has some forms for other birds such as, 咯咯 'gē gè' for chicken clucking, 咕咕咕 'gū gū gū' for roster crowing and 嘎嘎 'gā gā', 呱呱 'guā guā' for duck calling. One can notice that the sound of the same kind of bird might be articulated differently across the three languages.

Because of some religious restrictions on the consumption of pork, Arabic speakers are not familiar with pigs and hence Arabic has no onomatopoeic expression for pig grunting and pig squealing while English does, it selects oink oink and bree bree, respectively. Arabic, furthermore, does not differentiate between sheep bleating and goat bleating using مباع 'mbaa' 'maa' to depict both while English typically selects baa for sheep bleating and maa or naa for goat bleating. Mandarin Chinese typically selects also one form for both 咩 'miē'. English, interestingly, might have different forms for the same sound across different varieties such as miaow (British English) and meow (American English) for cat meowing and for frog croaking, for instance, ribbit, gribbit in American English and croak in British English. Whereas, Arabic and Mandarin Chinese select only one form across the different varieties نقيق 'naqiq' and 呱呱 'guā guā', respectively.

More examples are listed in Table 1 that can show the similarities and differences amongst the three languages. It demonstrates the existence and amount of the affiliation among Arabic, English and Mandarin Chinese onomatopoeic words. However, it shows that there is not such a flawless one-to-one relationship. Despite some likeness that exist among them, there are plenty of differences. On the basis of the history of onomatopoeic words, the same meaning might be delivered differently mapped onto uncomparable forms across the three languages. The differences might occur phonetically, lexicologically, morphologically, and semantically as well. 
Table 1. Examples of onomatopoeias across the three languages

\begin{tabular}{|c|c|c|c|}
\hline & & Forms & \\
\hline \multirow[t]{2}{*}{ Meaning } & L1: & L2: & L3: \\
\hline & Arabic & English & Mandarin Chinese \\
\hline \multirow[t]{2}{*}{ Cow mooing } & 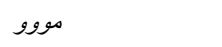 & moo & 哞 \\
\hline & 'moo' & & 'mōu' \\
\hline \multirow[t]{2}{*}{ Laughing } & هـ & haha, heh-heh, hoho, (tee)heehee & 哈哈 \\
\hline & 'hà hà' & & $\begin{array}{l}\text { 'hā hā' 呵呵 'hē hê', 嘻嘻 ‘xī xî̀' and } \\
\text { 嘿嘿 'hēi hēi' }\end{array}$ \\
\hline \multirow[t]{2}{*}{ Baby crying } & وع & wah-wah & 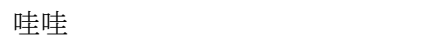 \\
\hline & 'waa'-waa' & & 'wā wā' \\
\hline \multirow[t]{3}{*}{ Cat meowing } & 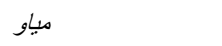 & miaow (UK), meow (US), miau & 喵 \\
\hline & 'muwà' & & 'miāo' \\
\hline & مُواَء 'muwà-' & & \\
\hline \multirow[t]{2}{*}{ Screaming } & 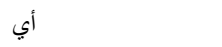 & ah, arghh ow, ouch, yeow, yow, agh, & 啊 ‘ā', 嗯 ‘ō', 䒝呀 ‘āiyā', 䒝哟 \\
\hline & ‘ai’ & eek, yikes, oof & 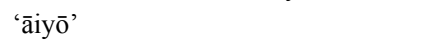 \\
\hline \multirow[t]{2}{*}{ Pausing } & 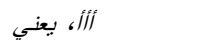 & uh, um, er, erm, hmmm, $\mathrm{mmm}$ & 嗯 \\
\hline & 'y'ani, aaaa' & & 'èn’ \\
\hline \multirow[t]{2}{*}{ Kissing } & مواح & mwah, smooch, smack & 皮 \\
\hline & 'mwah' & & 'boh' \\
\hline Car horn & بيب بيب، طيط طيط & honk honk, beep beep, toot toot & 叭叭 \\
\hline honking & beeb beep' 'titit-tit' & & 'ba ba' \\
\hline \multirow[t]{2}{*}{ Crashing } & بوم، طاخ، طراخ & boom, bam, wham, slam, bang, & 轰 \\
\hline & bom, tàkh, tràkh & crash, clash, pow, thud, clang & 'hong' \\
\hline \multirow[t]{3}{*}{ Clock ticking } & تيك تيك & tick-tock & 嘀嗒 \\
\hline & 'tick tick' & & 'dí dā’ \\
\hline & صه، هوص & hush, shh, shush & 噓 \\
\hline Hushing & 'suh, hoss' & & 'xū' \\
\hline Chicken & بق بق بيق & bok bok & 咯咯 \\
\hline clucking & 'baq baq baiq' & & 'gē gē' \\
\hline Camera & تشك تثك & click & 咔嚓 \\
\hline shuttering & 'chic chic' & & 'kā chā' \\
\hline \multirow[t]{2}{*}{ Knocking } & 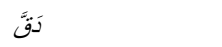 & knock knock, bang bang bang & 当当当 \\
\hline & 'daqqa' & & 'dang dang dang' \\
\hline \multirow[t]{2}{*}{ Water dripping } & تيك تبك، تبك توك & drip drop, plink plonk & 滴答 \\
\hline & 'tik tik or tok tok' & & 'dī dá' \\
\hline
\end{tabular}

The analysis lends further support to the lexical root. The main argument suggests that all world languages are inherently related is, thus, true. There are not only several similarities between Arabic, English and Chinese onomatopoeic words, but also relatively enormous dissimilarities exist in some cases. Table 1 demonstrates that Arabic and Mandarin Chinese onomatopoeic words are relatively counterparts for sharing some identical forms and meanings. Their dissimilarities, nevertheless, are because of natural reasons and dissimilar avenues of phonetic, morphological and semantic variation. To summarise, based on the aforementioned analysis, onomatopoeic expressions can be classified into two main groups: 1) corresponding forms as in hushing, and 2) non-corresponding forms as in barking. The latter is subdivided into two subgroups: 2a) non-corresponding forms for the L3 only (as the L1 and L2 forms are relatively comparable, yet they might not be quite identical) such as in kissing. And 2b) non-corresponding forms across the three languages (i.e., each language has unequal unique form as it articulates the same meaning in a language-specific manner) such as in camera shuttering as Table 1 shows.

Taken together, Arabic learners of English might find, for instance, the onomatopoeic expression for dog or wolf howling effortless to master in the L2 since both their L1 and the target language have corresponding forms 'awoooo' in Arabic and awooo in English. While they are likely to encounter more challenge with other forms that are not corresponding such as woof, arf, bow wow, ruff, yap yap and نبا 'ماو هاو 'nibaah' 'haw', in English and Arabic, respectively. This difficulty is expected to be greater when it comes to mastering the same sound in Mandarin Chinese 汪汪 'wāng wāng' as the form in the target language is not corresponding to any of those of the former acquired languages neither L1 or L2. More interestingly, Arabic learners might be familiar with only one form but not the others particularly when the target language makes use of several representations to mirror the same meaning or a relatively related meaning such as the onomatopoeic expressions depicting screaming as Table 
1 demonstrates. Hence, lexico-sematic transfer is predictable to occur especially at early stages of L3 development.

\subsection{Lexico-Semantic Transfer}

L3 is described as any other language mastered after the L1, and could thus stands for mastering of a second, third, fourth or fifth language. De Angelis (2008, p. 11) defines L3 as "all languages beyond the L2 without giving preference to any particular language." The source of transfer to the interlanguage of learners of their first foreign languages is their L1s. Nevertheless, identifying that source is not always quite clear-cut, especially for multilingual speakers. Several studies endeavour to account for the process of mastering an L3 and to determine the dissimilarities with regards to the acquisition of an L2 (Herdina \& Jessner, 2000). Pinto (2013) argues that multilingual learners, who have already acquired at least one more language, plus their L1s, have a definite familiarity compared to learners of their first L2. That is, they have a superior metalinguistic awareness and superior familiarity in the formal and informal methods of acquiring languages. The latter are beginners in mastering an L2 and only has their L1s as a starting point. The former has already established linguistic awareness and obtained some learning strategies of one or more foreign languages that may perhaps assist their access to the L3 development (Rothman et al., 2011; Pinto, 2013). Therefore, they are likely to be more proficient and have a distinct competence (Jessner, 1999; Grosjean, 2001). In these cases, learners are more likely to overcome the lack of familiarity in mastering the L3 relying on not only their L1s but also, and perhaps mostly, the L2.

Likewise, Odlin $(1989$, p. 27) argues that the interlanguage is attributed to "(..) similarities and differences between the target language and any other language that has been previously (and perhaps imperfectly) acquired", taking into account both the former familiarity of the L1 and of any other non-native languages. Smith (1994) defines transfer with reference to the impact of the L1 and of any other languages previously learned. Several studies (e.g., De Angelis \& Selinker, 2001; Hammarberg, 2001; Pinto, 2013) have even provided some evidence that transfer might take place mostly from the L2 and not from the L1. In these circumstances, during the course of L3 development, learners frequently produce patterns of interlanguage that are partially or entirely patterns of the L2. Dewaele (1998, p. 488) states that " (...) the active language with the highest level of activation is the preferred source of lexical information. Access to lemmas of languages that have a lower level of activation is partially blocked. It appears that the $\mathrm{L} 1$ is not necessarily always the dominant active language and that access to its lemmas could accordingly be limited". Pinto (2013) argues when learners have formerly mastered more than one language, this makes mastering an L3 more problematic than that of an L2. According to Rothman et al. (2011, p. 7), they “(...) have more sources for initial state hypotheses than a monolingual L2 learner". While several researchers have demonstrated that the L1 is a fundamental source of transfer, others (e.g., Dewaele, 1998; Pinto, 2013) have established that other languages may also have an essential role in mastering an L3 and being the key source of transfer. According to the latter group, foreign languages, alongside the L1, are considered possible sources of language transfer. Several lines of evidence suggest that transfer takes place because of a foreign language influence and not of the L1 (e.g., Hammarberg, 2001; Pinto, 2013). Furthermore, several studies have discussed the factors that affect the transfer of an L2 such as psychotypology, exposure to foreign languages, language proficiency and the 'foreign-ness' of words. For a detailed account of the aforementioned factors, lexical-transfer occurs as stated by Pinto (2013).

Lexical transfer is a fundamental cognitive development in mastering a foreign language. Learners determine correspondences between words of the formerly mastered languages and those of the L3 and, based on this interlinguistic association, they transfer lexical entries they assume equal. Lexical transfer can be demonstrated in two methods: by transferring forms as well as transferring meanings (De Angelis \& Selinker, 2001). The former is related to using words obtained from other languages formerly mastered, or not to the configurations of the words of the target language. The latter is related to transferring semantic configurations of lexical elements of the L1 and/or of the foreign languages for the entities of the L3 as "semantic calques" as Pinto (2013) has described them. Most studies examining lexical transfer in L3 acquisition have examined cases in which L1, L2 and L3 were all European languages. Therefore, according to Freundlich (2016), most of the findings reported in these studies are related to false friends and borrowings. Freundlich (2016) argues that in any learning situation of European L1 and L2 and Mandarin Chinese L3, it is unlikely to be attributed to lexical transfer; certainly, lexical transfer will perhaps take place less recurrently than in an all-European situation and any instances of lexical transfer in circumstances such as that is to be reported in the current study can, possibly, be more precisely defined as semantic transfer. Ringbom (2001) argues that semantic transfer is mostly L1-based. He differentiates between non-target like patterns based on forms and those based on meanings, stating that the former (i.e., forms) are largely influenced by L2, whereas the latter (i.e., meanings) are mostly influenced by the learners' L1.

Furthermore, few studies on transfer in L3 acquisition discuss the role of the language of instruction. Freundlich (2016) reported only one study that touched upon the issue, which was conducted by Musona and Mushangwe 
(2014), in which they examined native speakers of Shona learning Mandarin as L3 through the medium of English L2 in Zimbabwe. They examined their use of Mandarin Chinese prepositions. However, Freundlich (2016) argues that their findings are not definite, although they seem in favour of L1 influence: "The survey shows that though the acquisition of Chinese prepositions by native speakers of Shona is basically influenced by the students' own mother tongue (Shona), however, there is clear evidence that the language of instruction, which is English in this case, has its own contributions too" (Musona \& Mushangwe, 2014, p. 8).

\section{Statement of the Problem}

Khademi et al. (2014) argue that onomatopoeic expressions sound effortless to master as these forms have iconic nature. That is, there is an arbitrary association linking their forms and meanings and hence it is achievable to predict their meaning from their forms. Nevertheless, there potentially arises a considerable gap in establishing the relationship and this raises the question whether a one-to-one relationship does even exist between forms and meanings among onomatopoeic expressions across different languages and whether one can account entirely on the iconic nature of onomatopoeic expressions? Few studies have examined the question of how learners having L1 (such as Arabic) with a small number of onomatopoeic expressions acquire languages (such as Mandarin Chinese) as compared to L1 that possesses a huge number of onomatopoeic expressions. Thus, the current study will offer a slightly new standpoint of cross-linguistic transfer in L3 acquisition in a new context.

\section{Research Methodology}

\subsection{Research Questions}

This study attempts to answer the following questions:

1) Do Arabic learners of Mandarin Chinese find onomatopoeic expressions corresponding to their mother tongue (L1) easy to comprehend?

2) Do Arabic learners of Mandarin Chinese find onomatopoeic expressions non-corresponding to their L1 easy to comprehend?

3) Is there any statistically significant difference in the level of comfort among Arabic learners of Mandarin Chinese in comprehending onomatopoeic expressions corresponding to their L1 and onomatopoeic expressions non-corresponding to their L1?

4) What kind of learning methods do Arabic learners of Mandarin Chinese use in order to identify the target expressions?

\subsection{Null Hypothesis}

The study in hand aims to test the following null hypothesis:

$\mathrm{H}_{0}$ : There does not exist any statistically significant difference among Arabic learners of Mandarin Chinese in comprehending onomatopoeic expressions corresponding to their L1 and onomatopoeic expressions non-corresponding to their L1.

\subsection{Alternative Hypothesis}

The study has the following alternative hypothesis:

$\mathrm{H}$ : There exists statistically significant difference among Arabic learners of Mandarin Chinese in comprehending onomatopoeic expressions corresponding to their L1 and onomatopoeic expressions non-corresponding to their $\mathrm{L} 1$.

\subsection{Research Design}

The research in hand used mixed methodology in which the quantitative component, which records the performance of the participants on a test, was prepared to identify their acquisition of onomatopoeic expressions corresponding to their L1 and onomatopoeic expressions non-corresponding to their L1. In order to answer the research question, the participants had to do translation task. The translation task took approximately 20 minutes. It consisted of 20 onomatopoeic expressions in Mandarin Chinese. The participants were instructed to translate the given items. Given that the learners are not familiar yet with the written forms of the target language, they were given the original forms (i.e., Mandarin Chinese) along with their English transliterations. The participants have been introduced to the target language one month prior to the experiment. The medium of the instruction was English and the introductory lessons were launched twice a week via a Telegram channel. Before administering the task, the researcher clarified in English and Arabic what the participants were expected to do so as to clarify the task and eliminate any ambiguity and doubt about the procedures. Likewise, they were given a short explanation about onomatopoeic expressions. They were instructed to translate all the items. Even if they 
do not recognize one in the translation test, they must attempt to translate it into their Arabic counterpart by means of their background familiarity and their guessing aptitude and their intuitions (since onomatopoeic expressions are iconic and it is rational to anticipate the participants may identify them by guessing). Afterwards, and in order to answer the research question related to the methods that Arabic learners of Mandarin Chinese use to identify the target expressions and if the L2 has any role in L3 development, there was an open-ended interview in which the participants were asked why they translated a particular item into a specific equivalent so as to find out their justifications.

\subsection{Instrumentation}

The main instrument was a 20-item test to record performance of Arabic learners of Mandarin Chinese in comprehending onomatopoeic expressions corresponding to their L1 and onomatopoeic expressions non-corresponding to their L1. All the 20 onomatopoeic words were selected after planning a list of the most common onomatopoeic expressions from a wide range of sources (e.g., comic strips, comic books, advertisements, dictionaries, websites) and their English and Mandarin Chinese counterparts were taken from a digital translation tool, Chinese-Tools.com, that facilities translating from Arabic and English to Mandarin Chinese. Comic strips and comic books include wide-ranging onomatopoeic words (e.g., bang, bam, pow, boom, wham). Recently, many onomatopoeias were added as a feature for digital communications such as Snapchat, including muah, ouch, oops, oh, he he he, yum, woot, uhhhh, etc. Common and familiar English onomatopoeic expressions that are used in this modern platform were also included. The test items included two types of onomatopoeic expressions: 1) corresponding items that sound relatively equal across the three languages (e.g., 哈哈 'hā hā' depicting laughing), and 2) non-corresponding items across the three languages (e.g., 嗡嗡 'wēng wēng' portraying bee buzzing). See Table 1 for their Arabic and English counterparts. The second instrument was an open-ended interview protocol to elicit the responses of the participants of the study related to methods used to understand the onomatopoeic expressions.

\subsection{Participants of the Study}

The researcher randomly selected 45 English-major female students from Department of Foreign Languages, Taif University, Saudi Arabia. Those students were native speakers of Arabic (of its two varieties - standard Arabic and dialectal 'Saudi Arabic') and were exposed to only one non-native language (i.e., English) in formal and informal learning contexts. They studied English as a foreign language for about 9 years. English was used as the language of instruction, not Arabic. However, none of them were studying Mandarin Chinese as it is still not introduced in the curriculum.

\subsection{Data Analysis}

The researcher has manually entered the data and run paired-samples t-test to identify whether any statistically significant difference exist among Arabic language of Mandarin Chinese in acquiring onomatopoeic expressions corresponding to their L1 and onomatopoeic expressions non-corresponding to their L1. The qualitative data generated through the interview will be presented in terms of their responses to identify the answer to the relevant research questions.

\section{Results and Findings}

Paired-samples t-test was conducted to compare the learners' performance on onomatopoeic expressions corresponding to their L1 (henceforth called Type 1) and on onomatopoeic expressions non- corresponding to their L1 (henceforth called Type 2). There was a significant difference in the scores for Type1 $(M=9.84, S D=.37)$ and Type $2(M=.58, S D=.83)$ conditions; $\mathrm{t}(44)=64.55, p=0.000$. These results suggest that the speakers significantly performed much better on Type 1 (i.e., corresponding forms) than Type 2 (non-corresponding forms). Specifically, the results suggest that when the target onomatopoeic expressions are matching those of the speakers' L1, they significantly perform much better as Table 2 demonstrated. Hence, the null hypothesis is rejected in favour of the alternative hypothesis.

Table 2. Descriptive and paired samples t-test comparing between Type 1 and Type 2

\begin{tabular}{llllllll}
\hline Types & Mean & $\mathrm{N}$ & Std. Deviation & Std. Error Mean & $\mathrm{t}$ & $\mathrm{df}$ & Sig. (2-tailed) \\
\hline Type 1 & 9.84 & 45 & .37 & .055 & 64.55 & 44 & $\mathbf{. 0 0 0}$ \\
Type 2 & .58 & 45 & .83 & .12 & & & \\
\hline
\end{tabular}

Note. $*$ The mean difference is significant at the 0.05 level. 
Generally speaking, one of the more significant findings to emerge from this study is that learners performed with a high degree of accuracy on Type 1. On the other hand, there was relatively low rate of acceptable representations on Type 2. Evidence of transfer was found not only from the L1 but also from L2. This suggests that the L1 does not always have a dominant role in the L3 acquisition, particularly in lexicon. That is, learners rely heavily on their L1 knowledge. That is, the evidence from the current study suggests that semantic transfer from L1 to L3 played a significantly greater role. Learners struggled with a number of Mandarin onomatopoeic expressions which do not exist in L1. One noticeable difference observed was some speakers produced unacceptable L3 patterns which correspond exactly to English. This was found to be the case even when there were greater similarities between L1 and L3 lexicon than between L2 and L3 lexicon. Although Chinese Mondrian is largely unrelated to neither the L1 nor the L2, there were some non-target like patterns based on forms (e.g., false friends) triggered by the L2. Moreover, there were some instances of non-target like patterns based on phonological resemblance triggered by L1.

Pushing the discussion one step further, based on the responses of the open-ended interview and after categorizing the participants' responses, their justifications were classified into four categories as follow: phonological resemblances, L1 knowledge (i.e., Arabic), L2 knowledge (i.e., English) and guessing. The majority of participants agreed with the statement that the target forms are similar to those of their L1 or L2. This view was echoed by other participants who found the phonetical resemblance a helpful clue. However, it was not always helpful.

To exemplify, Arabic speakers find some Mandarin Chinese onomatopoeic expressions such as the one denotes crow calling 哑哑 'yā yā' quite challenging as it does not correspond to either قاقاق 'qù qà', نعبيب 'na'eeq', 'na'eeb' in Arabic nor caw caw in English. Likewise, the form that represents snoring in Mandarin Chinese 呼噜 'hū lū' looks unfamiliar to them as it does not phonetically correspond to neither خششش' 'akhush akhush' in Arabic nor ZZZ in English. Equally, they could not correctly translate the form portraying bees buzzing 嗡嗡 'wēng wēng' for the same reason; i.e., both the L1 and the L2 select incomparable forms دوي 'dwii' and $b u z z$ or $b z z z$, in Arabic and English, respectively. More interestingly, they could not identify the meanings of Mandarin Chinese onomatopoeic expressions that do not exist in their L1 such as 唰 'shua' the sound symbolises brushing teeth in Mandarin Chinese, even though their L2 English has one that is not even corresponding chika chika. However, they successfully identify the form 阿德 'à tì' portraying sneezing 'hatchu' in Arabic and atishoo and achoo in English although it is not quite matching to their L1. Similarly, they found Mandarin Chinese onomatopoeic expression used for snake hissing 嘶嘶 ( $s \bar{\imath} s \bar{l}$ ) less challenging although it is not equivalent to the form of their L1 Arabic فحيح 'fahih' nor the L2 English hiss or ssss. Maybe, this was due to phonological resemblances or guessing as they clarified later in the interview.

More interestingly, there were several justifications for the L2 to be one of the triggers to transfer. It was claimed that one factor resulting in the predominance of L2 transfer in the realm of lexical semantics was the fact that L2 (i.e., English) was the language of instruction. This support evidence comes from several studies (e.g., Williams \& Hammarberg, 1998; Pinto, 2013) which suggest that the recent practice of L2 assists transferring to the L3, attributed to the easy and direct access to the linguistic information stored in their memory. That is, they claim that the recent practice of an L2 is a key factor that trigger transfer during the L3 development. Hammarberg (2001, p. 23) supports this process and states that the "L2 is activated more easily if the learner has used it recently and thus maintained easy access to it". This is quite evident if we consider using today social media and digital communication platforms such as Snapchat which largely makes heavy use of countless of Bitmoji along with related English onomatopoeic expressions. Furthermore, several studies (Hammarberg, 2001; Ringbom, 2001; Pinto, 2013) addressed the role of typology in the development of an L3 and suggest that the typological proximity linking an L2 and an L3 is likely to assist the lexical-semantic transfer, mainly if the L1 is more distant. Hence, in the circumstances where the mother language is typologically distant from the target language, learners are likely to activate their knowledge of L2 that is formerly mastered, which is supposed to be the closest and transfer consequently occurs (De Angelis, 2008).

Furthermore, one should bear in mind that although this study takes into consideration the level of proficiency in the L3 and how the low knowledge affects language transfer. The finding lends support to Pinto (2013) who claims that transfer commonly takes place in the early phases of language development while the learners' knowledge of the L3 is still limited and they attempt to fill the gaps they come across in it. Moreover, the findings support the finding of Hammarberg (2001) and Ringbom (2001) who argue that transfer of L2 to the L3 is favoured if the learners have a relatively high proficiency in the L2, particularly if this language was mastered and commonly functioned in common contexts.

The findings of this study have a number of important implications for future practice, especially for pedagogical 
aspects. Enhancing awareness of lexical transfer through focused consideration of the common problems seems crucial for L3 learners to attain comprehensive mastery. This could be achieved through explicitly enlightening of the gaps between the L1, L2 and the L3 systems showing that a single sound might be articulated differently in a language specific way across the world. Increasing awareness towards such complex relationship linking meaning and forms seem a reasonable approach though which learners can overcome cases of L3 poor comprehension.

\section{Conclusion}

It is evident that cross-linguistic transfer takes place during the course of L3 development and that the influence may be attributed to not only L1 but also L2. This study attempts to determine the extent to which transfer from L1 affected L3 development and to determine the circumstances in which L1 was the prevailing influence. The purpose of the current study is to determine the role of transfer from L1 in influencing L3 comprehension. At the lexico-semantic level, this study examines onomatopoeia as a property of L3 acquisition that requires Arabic learners of Mandarin Chinese to identify new lexicons with meanings and functions that have been delivered differently from the way they are in their L1. Given that onomatopoeia, in general, is often not taught sufficiently in many language classroom contexts. The learners are challenged with accommodating the L3 system, they are more likely to lean somewhat heavily on their pre-existing linguistic knowledge, making transfer unavoidable. Despite its exploratory nature, this study offers some insights into one major issue that might create problems for Arabic learners of Mandarin Chinese. The study concludes that enhancing awareness of lexical transfer through a focused consideration of the common difficulties seems crucial for L3 learners to attain comprehensive mastery.

\section{Recommendations}

Finally, the current study recommends taking these findings into consideration and lends support to Arabic learners of Mandarin Chinese by carrying out research on difficulties of learning Mandarin Chinese as L3 and learners' anxieties before implementation. Teaching Mandarin Chinese may take advantages of using up-to-date and learner-cantered teaching approaches. Furthermore, the Saudi government should increase learners' motivation towards learning Mandarin Chinese, for instance, by increasing future professions and opening new business in China. Before implementation, Arabic learners of Mandarin Chinese are recommended to be open to the Chinese culture if they want to master Mandarin Chinese effectively. Future research could develop the present findings by observing Arabic learners of Mandarin Chinese motivation and the use of modern trends of technology in $\mathrm{L} 3$ development.

\section{References}

Al-Jahidh. (1988). Kitabu al'-Haywan. Beirut, Lebanon: Al-Almiyya Books.

Al-Zubbaidi. H. K. (2014). The Functions of Onomatopoeia in Modern English and Arabic Poetry: A Study in Selected Poems by Lawrence and al-Sayyab. Advances in Language and Literary Studies, 5(6), 181-193. https://doi.org/10.7575/aiac.alls.v.5n.6p.181

Alameer, A. (2019). The Linguistic Features of Onomatopoeia Words in Arabic-English: Contrastive Study. International Journal of Humanities and Social Science Invention, 8(9), 06-12.

Althaaalibi, A. M. (2011). Fiqhu allughat wa asraar alarabiyyat (Ed. by Alayoobi, Dr. Yaseen. Beirut and Saida). Lebanon: Al-Maktabat Al-3aSriyyat.

Arab News. (February 22, 2019). Saudi Arabia plans to introduce Chinese into the curriculum at all education levels. Retrieved December 19, 2019, from https://www.arabnews.com/node/1456466/saudi-arabia

Bn Manzoor, \& Almisri, A. A. (2013). Lisan al3arab. Beirut, Lebanon: Dar Sadir.

Campbell, L. (2006). Historical linguistics: An introduction (2nd ed.). Cambridge, Mass.: The MIT Press. Retrieved March 2020, from https://www.chinesetools.com/chinese/vocabulary/list/130/onomatopoeias.html

De Angelis, G. (2008). Third Additional Language Acquisition. Clevedon: Multilingual Matters. https://doi.org/10.21832/9781847690050

De Angelis, G., \& Selinker, L. (2001). Interlanguage Transfer and Competing Linguistic Systems in the Multilingual Mind. In J. Cenoz, B. Hefeisen \& U. Jessner (Eds.), Cross-linguistic Influence in Third Language Acquisition: Psycholinguistic Perspectives (pp. 42-58). Clevedon: Multilingual Matters. https://doi.org/10.21832/9781853595509-004

Dewaele, J.-M. (1998). Lexical inventions: French interlanguage as L2 versus L3. Applied Linguistics, 19, 471-490. https://doi.org/10.1093/applin/19.4.471 
Falk, J. S. (1978). Linguistics and Language a Survey of Basic Concepts and Implications. New York, US: John Wiley \& Sons.

Freundlich, J. (2016). Cross-linguistic influence in third-language acquisition: Learning Mandarin Chinese (L3) through the medium of English (L2). Państwo i Spoleczeństwo, 16(3), 11-32.

Fromkin, V., Rodman, R., \& Hyams, N. (2003). An introduction to language (7th ed.). Thompson Heilne.

Grosjean, F. (2001). The Bilingual's Language Modes. In J. L. Nicol (Ed.), One Mind, Two Languages: Bilingual Languages Processing (pp. 1-22). Oxford: Blackwell.

Hammarberg, B. (2001). Roles of L1 and L2 in L3 Production and Acquisition. In J. Cenoz, B. Hefeisen \& U. Jessner (Eds.), Cross-linguistic Influence in Third Language Acquisition: Psycholinguistic Perspectives (pp. 21-41). Clevedon: Multilingual Matters. https://doi.org/10.21832/9781853595509-003

Harper, D. (2014). Online etymology dictionary. Retrieved April 15, 2014, from http://www.etymonline.com

Herdina, P., \& Jessner, U. (2000). The dynamics of a third language acquisition. In J. Cenoz \& U. Jessner (Eds.), English in Europe-The Acquisition of a Third Language (pp. 84-98). Clevedon: Multilingual Matters.

Ibn Seedah, A. B. I. (1996). AlmukhaSSaS. Beirut, Lebanon: Daar I2ya Alturath Al3arabi and Muassasat Altareekh al3arabi.

Jassem, Z. A. (2014). The Arabic Origins of "Mandarin Chinese Pronouns": A Radical Linguistic Theory Approach. International Journal of English and Education, 3(3), 530-555.

Jessner, U. (1999). Metalinguistic Awareness in Multilinguals: Cognitive Aspects of Third Language Learning. Language Awareness, 8(3\&4), 201-209. https://doi.org/10.1080/09658419908667129

Kambuziya, A., \& Zeinoalbedin, R. (2014). A Comparison between Onomatopoeia and Sound Symbolism in Persian and English and Their Application in the Discourse of Advertisements. International Journal of Basic Sciences \& Applied Research, 3(SP), 219-225.

Khademi, M., Aghili, H., \& Harati, H. (2014). How much Correlation Does Exist Between English and Farsi Onomatopoeic Words? International Journal of Language Learning and Applied Linguistics World, 6(1), 504-513.

MaÕrifatil, L. N. (2008). A Study of Onomotopoeia in Avatar Comics. Oxford university press (2000), Oxford Advanced Learner's Dictionary.

Musona, M., \& Mushangwe, H. (2014). An analysis of acquisition of Chinese prepositions by native speakers of Shona. International Journal of Education and Research, 2(2), 1-12.

Odlin, T. (1989). Language transfer. Cross-linguistic Influence in Language Learning. Cambridge, UK: Cambridge University Press. https://doi.org/10.1017/CBO9781139524537

Pinto, J. (2013). Cross-linguistic influence at lexical level. A study with Moroccan learners of Portuguese as an L3/LN. Revista Nebrija de Lingüistica Aplicada, 13, 3-50.

Pyles, T., \& Algeo, J. (1993). The origins and development of the English language (4th ed.). San Diego: HBJ.

Ringbom, H. (2001). Lexical transfer in L3 production. In J. Cenoz, B. Hufeisen \& U. Jessner (Eds.), Cross-linguistic influence in third language acquisition: Psycholinguistic perspectives (pp. 59-68). Clevedon: Multilingual Matters. https://doi.org/10.21832/9781853595509-005

Rothman, J., Iverson, M., \& Judy, T. (2011). Some notes on the generative study of L3 acquisition. Second Language Research, 27(1), 5-19. https://doi.org/10.1177/0267658310386443

Seyyedi, H., \& Akhlaghi, E. (2013). The Study of Onomatopoeia in the Muslims' Holy Write: Quran. Language in India, 13(5), 16-24.

Sharwood, S. M. (1994). Second Language Acquisition: Theoretical Foundations. London, UK: Longman.

Tamori, I., \& Schourup., L. (1999). Onomatope: Keitai to Imi (Onomotopoeia: Morphology and Semantics). Tokyo: Kurosio Publishers.

Thomas, D., \& Hill, F. (2012). Literary Special Effect, Onomatopoeia. Beverly Schmitt.

Williams, S., \& Hammarberg, B. (1998). Language switches in L3 production: Implications for a polyglot speaking model. Applied Linguistics, 19, 295-333. https://doi.org/10.1093/applin/19.3.295

Yaqubi, M., Tahir, R. I., \& Amini, M. (2018). Translation of Onomatopoeia: Somewhere between Equivalence 
and Function. Studies in Linguistics and Literature, 2(3), 205-222. https://doi.org/10.22158/sll.v2n3p205

Yi, K. (2005). Use of onomatopoeia in modern Chinese. In Z. L. Wu, S. Kai \& J. X. Lin (Eds.), Chinese Studies (vol. 8, pp. 355-359). Jinan: Jinan Publishers.

Yi, K. (2007). Onomatopoeias in Modern Chinese. Shanghai: Xuelin Publishers.

\section{Copyrights}

Copyright for this article is retained by the author, with first publication rights granted to the journal.

This is an open-access article distributed under the terms and conditions of the Creative Commons Attribution license (http://creativecommons.org/licenses/by/4.0/). 